\title{
Secondary Sjogren Syndrome
}

National Cancer Institute

\section{Source}

National Cancer Institute. Secondary Sjogren Syndrome. NCI Thesaurus. Code C116986.

Sjogren syndrome that occurs with another systemic autoimmune disorder, such as

systemic lupus erythematosus or rheumatoid arthritis. 